\title{
UCP2 expression may represent a predictive marker of neoadjuvant chemotherapy effectiveness for locally advanced uterine cervical cancer
}

\author{
KENJI IMAI, TAKESHI FUKUDA, TAKUMA WADA, MASARU KAWANISHI, \\ REIKO TASAKA, TOMOYO YASUI and TOSHIYUKI SUMI
}

Department of Obstetrics and Gynecology, Osaka City University Graduate School of Medicine, Osaka 545-8585, Japan

Received October 14, 2016; Accepted March 24, 2017

DOI: $10.3892 / \mathrm{ol} .2017 .6212$

\begin{abstract}
Concurrent chemoradiotherapy is the standard treatment for locally advanced uterine cervical cancer. However, effective neoadjuvant chemotherapy (NAC) can reduce tumor size and facilitate hysterectomy for locally advanced uterine cervical cancer. NAC treatment could improve the prognosis of patients with locally advanced cervical cancer. However, if NAC is ineffective, radiotherapy must be pursued. This causes a delay in initiating the core treatment and results in a worse prognosis. Therefore, the identification of predictive markers of whether NAC is likely to be effective for the treatment of locally advanced uterine cervical cancer could improve patient prognosis. Uncoupling protein 2 (UCP2) is broadly expressed in cancer cells, and suppresses mitochondrial reactive oxygen species (ROS) production. UCP2 contributes to both carcinogenesis and chemoresistance by reducing ROS. Downregulation of UCP2 results in significantly increased cell death following chemotherapy. The present study investigated the association between UCP2 expression and NAC effectiveness. A total of 58 patients with locally advanced uterine cervical cancer (stage IIIA or IIIB) treated at Osaka City University Hospital between April 1995 and March 2010 were examined. Tumor tissue samples were obtained by punch biopsy prior to NAC UCP2 expression was examined immunohistochemically and scored using a weighted scoring system. Patients were divided into NAC effective $(n=34)$ and ineffective $(n=24)$ groups. Furthermore, UCP2 expression in human uterine cervical cancer cells was inhibited by genipin, and changes in cisplatin sensitivity were examined. UCP2 weighted score was higher in the NAC ineffective group than in the NAC effective group $(\mathrm{P}=0.038)$. Additionally, the low UCP2
\end{abstract}

Correspondence to: Dr Takeshi Fukuda, Department of Obstetrics and Gynecology, Osaka City University Graduate School of Medicine, 1-4-3 Asahimachi, Abeno-ku, Osaka 545-8585, Japan

E-mail: takeshif@med.osaka-cu.ac.jp

Key words: uterine cervical cancer, uncoupling protein 2, neoadjuvant chemotherapy, predictive marker expression group was more sensitive to NAC than the high UCP2 expression group $(\mathrm{P}=0.041)$. Sensitivity to cisplatin was significantly increased when UCP2 was inhibited in human uterine cervical cancer cells in vitro. UCP2 expression may become a predictive marker of whether NAC is effective for patients with locally advanced uterine cervical cancer, which could improve patient prognosis.

\section{Introduction}

Uterine cervical cancer is the second most frequent cancer in women, causing cancer-associated mortality worldwide (1). Concurrent chemoradiotherapy (CCRT) is the standard treatment for locally advanced uterine cervical cancer, including International Federation of Gynecology and Obstetrics (FIGO) stage IIIA, IIIB and IVA lesions (2-4) However, the prognosis of patients with locally advanced uterine cervical cancer is poor, and the 5-year survival rate is $<60 \%(5,6)$.

Effective neoadjuvant chemotherapy (NAC) can reduce tumor size to facilitate hysterectomy and improve the prognosis of patients with locally advanced cervical cancer (7). However, NAC is ineffective in certain cases, leaving radiotherapy as the only treatment option, and thereby delaying the initiation of the core treatment, thus resulting in worse prognosis $(8,9)$. At present, no significant predictive markers of NAC efficacy for locally advanced cervical cancer patient prognosis have been reported. The identification of such markers would improve therapeutic decision making and the prognosis of patients with locally advanced cervical cancer (10-14).

Chemotherapeutic agents generate reactive oxygen species (ROS) that can overwhelm antioxidant defenses to result in cell damage and cell death (15-17). Uncoupling proteins (UCPs) are mitochondrial anion transporters $(18,19)$. The five known types of UCP (UCP1-5) have different levels of identity and different tissue distribution (20). UCP1 is expressed in brown adipose tissue, which generates heat through uncoupling of oxidative phosphorylation from the electron transport chain (20). UCP2 expression has been identified in the liver, pancreas, adipose tissue, spleen, kidney and brain, and UCP3 is localized to skeletal muscle (20). UCP2 and UCP3 are activated by superoxide from the mitochondrial inner membrane, and can reduce ROS generation (21). UCP4 and UCP5 are specifically localized 
to the brain, and associated with reducing the mitochondrial membrane potential (22).

UCP2 is broadly expressed in cancer cells $(23,24)$, and can suppress mitochondrial ROS production, thus mitigating oxidative stress (25). Loss of UCP2 function may increase ROS production (25), whereas UCP2 overexpression may promote cytoprotection by mitigating oxidative stress $(26,27)$. Furthermore, UCP2 contributes to both carcinogenesis and chemoresistance $(28,29)$. UCP2 is implicated in human colon carcinogenesis $(24,30)$, while mitochondrial uncoupling by UCP2 induces pancreatic cancer cell resistance to gemcitabine (28). Furthermore, inhibition of UCP2 by genipin sensitizes cancer cells to chemotherapeutic agents $(28,29)$. These findings suggest that UCP2 represents a target for cancer treatment with chemotherapeutic agents that promote oxidative stress. In the present study, a correlation between UCP2 expression and the efficacy of NAC for locally advanced uterine cervical cancer was revealed.

\section{Materials and methods}

Patients and samples. The present study included 58 patients with locally advanced uterine cervical cancer (FIGO stages IIIA and IIIB). All patients were under 70 years of age, and were treated at Osaka City University Hospital (Osaka, Japan) from April 1995 to March 2010. Tumor tissue samples were obtained by punch biopsy prior to NAC. Patients were divided into two groups based on NAC effectiveness. For the NAC effective group, surgery was possible, and radiation therapy was also performed $(n=34)$, while in the NAC ineffective group, radiation therapy was performed without prior surgery $(n=24)$. All patients underwent balloon-occluded arterial infusion chemotherapy for NAC. Cisplatin (Bristol-Myers Squibb, Tokyo, Japan) was infused intra-arterially through the catheter over $30 \mathrm{~min}(31)$.

Written informed consent was obtained from all patients prior to punch biopsy. The present study was approved by the institutional review board (IRB) of Osaka City University Hospital (IRB no. 3524).

Immunohistochemical staining. UCP2 expression was examined in paraffin-embedded sections using an anti-UCP2 antibody (\#ab116263; Abcam, Cambridge, UK) and a Dako LSAB2 Peroxidase kit (\#K0675; Agilent Technologies, Inc., Santa Clara, CA, USA). Sections ( $4 \mu \mathrm{m}$-thick) were deparaffinized, rehydrated and immersed in $3 \%$ hydrogen peroxide at room temperature for $10 \mathrm{~min}$ to block endogenous peroxidase activity. An antigen retrieval procedure was performed by immersing sections in $10 \mathrm{mM}$ citrate buffer (pH 6.0) and heating to $110^{\circ} \mathrm{C}$ for $20 \mathrm{~min}$ in an autoclave. Tissue sections were then washed in PBS and incubated overnight at $4^{\circ} \mathrm{C}$ with a $1: 100$ dilution of the aforementioned rabbit polyclonal anti-UCP2 antibody. Next, sections were washed in PBS for $15 \mathrm{~min}$ and then incubated for 10 min with biotinylated goat anti-mouse or anti-rabbit immunoglobulin G (Dako; Agilent Technologies, Inc.). Sections were then incubated with a streptavidin-peroxidase complex, and 3,3'-diaminobenzidine was used as the chromogen. Finally, tissue sections were counterstained with $H \& E$ and the specificity of the immunohistochemical reactions was verified by omitting the primary antibody.
UCP2 expression levels were assessed quantitatively using the weighted score method of Sinicrope et al (32). The mean percentage of stained tumor cells was scored as follows: $0, \leq 5 \%$; $1,5<$ and $\leq 25 \% ; 2,25<$ and $\leq 50 \% ; 3,50<$ and $\leq 75 \% ; 4,>75 \%$. Staining intensity was classified into three categories: $1+$, weak; $2+$, moderate; and $3+$, intense. The weighted score was determined by multiplying the score of percentage of stained tumor cells by that of staining intensity for each tissue specimen.

Cell culture. The human uterine cervical cancer cell line Ca Ski (no. IFO50007; Japanese Collection of Research Biosources Cell Bank, Osaka, Japan) was maintained in RPMI medium (Gibco; Thermo Fisher Scientific, Inc., Waltham, MA, USA) with $10 \%$ fetal bovine serum (Gibco; Thermo Fisher Scientific, Inc.). Cells were cultured in a humidified atmosphere of 5\% $\mathrm{CO}_{2}$ and $95 \%$ air at $37^{\circ} \mathrm{C}$.

Immunofluorescence staining. Cells were seeded at a density of $4 \times 10^{3}$ cells/well in 4-well chamber slides. After $48 \mathrm{~h}$, the culture medium was removed, and the cells were washed three times in PBS. Cells were fixed with cold ethanol at $4^{\circ} \mathrm{C}$ for $10 \mathrm{~min}$ and then washed three times in PBS. Samples were blocked with $1 \%$ bovine serum albumin (Gibco; Thermo Fisher Scientific, Inc.) in PBS for $30 \mathrm{~min}$ at room temperature. Upon washing with PBS, samples were incubated with an anti-UCP2 antibody (1:250 dilution; no. scb-sc6525; Santa Cruz Biotechnology, Inc., Dallas, TX, USA) overnight at $4^{\circ} \mathrm{C}$. Upon washing with PBS, cells were exposed to a fluorescein isothiocyanate-conjugated anti-goat secondary antibody (1:200 dilution; no. F-2761; Dako, Agilent Technologies, Inc.) for $1 \mathrm{~h}$ at room temperature. Immunofluorescent images were captured using a fluorescence microscope (BX50; Olympus Corporation, Tokyo, Japan).

Chemosensitivity assay. The sensitivity of cells to cisplatin was examined using Cell Counting kit-8 (CCK-8; Dojindo Molecular Technologies, Inc., Kumamoto, Japan). Approximately $1 \times 10^{3}$ cells were seeded into each well of a 96-well tissue culture plate, and $24 \mathrm{~h}$ later, the culture medium was removed from each well and replaced with $100 \mu$ fresh medium. Next, $100 \mu \mathrm{l}$ dimethyl sulfoxide (DMSO) or DMSO containing $1 \mu \mathrm{M}$ genipin (\#G-4796; Sigma-Aldrich; Merck KGaA, Darmstadt, Germany) was added to each well. Cells were then treated with cisplatin $(0-10 \mu \mathrm{g} / \mathrm{ml})$ for $24 \mathrm{~h}$. Subsequently, $10 \mu \mathrm{l} \mathrm{CCK}-8$ was added, followed by $2 \mathrm{~h}$ of incubation. The absorbance at $450 \mathrm{~nm}$ was then measured with a microplate reader (Corona Electric Co., Ltd., Ibaraki, Japan). Dose-response graphs were constructed based on the percentage of viable cells compared with that of control untreated cells.

Statistical analysis. Data are presented as the mean \pm standard deviation in tables and as the mean + standard error in figures. Kaplan-Meier and log-rank analyses were performed to evaluate prognosis. Weighted scores were compared using the Mann-Whitney U test. Student's t was performed to identify significant differences between the means of two groups, and $\chi^{2}$ tests was performed identify the association between the categorical variables of two groups. SPSS software version 21.0 (IBM SPSS, Armonk, NY, USA) was used for all statistical analyses. $\mathrm{P}<0.05$ was considered to indicate a statistically significant difference. 
Table I. Characteristics of patients in the NAC effective and ineffective groups.

\begin{tabular}{|c|c|c|c|}
\hline Characteristics & NAC effective (no.) & NAC ineffective (no.) & P-value \\
\hline No. of patients & 34 & 24 & \\
\hline Age (years) & & & $0.394^{\mathrm{a}}$ \\
\hline Mean \pm SD & $49.3 \pm 12.9$ & $52.2 \pm 11.7$ & \\
\hline Range & 24-69 & $36-68$ & \\
\hline FIGO stage & & & $0.397^{\mathrm{b}}$ \\
\hline IIIA & 1 & 0 & \\
\hline IIIB & 33 & 24 & \\
\hline Histology & & & $0.400^{\mathrm{b}}$ \\
\hline $\mathrm{SCC}$ & 29 & 19 & \\
\hline A & 5 & 3 & \\
\hline AS & 0 & 1 & \\
\hline Others & 0 & 1 & \\
\hline Tumor size (mm) & & & $0.144^{\mathrm{a}}$ \\
\hline Mean \pm SD & $46.9 \pm 17.2$ & $53.7 \pm 14.9$ & \\
\hline
\end{tabular}

${ }^{a}$ Student's t-test. ${ }^{b} \chi^{2}$ test. NAC, neoadjuvant chemotherapy; FIGO, International Federation of Gynecology and Obstetrics; SCC, squamous cell carcinoma; A, adenocarcinoma; AS, adenosquamous carcinoma; SD, standard deviation.
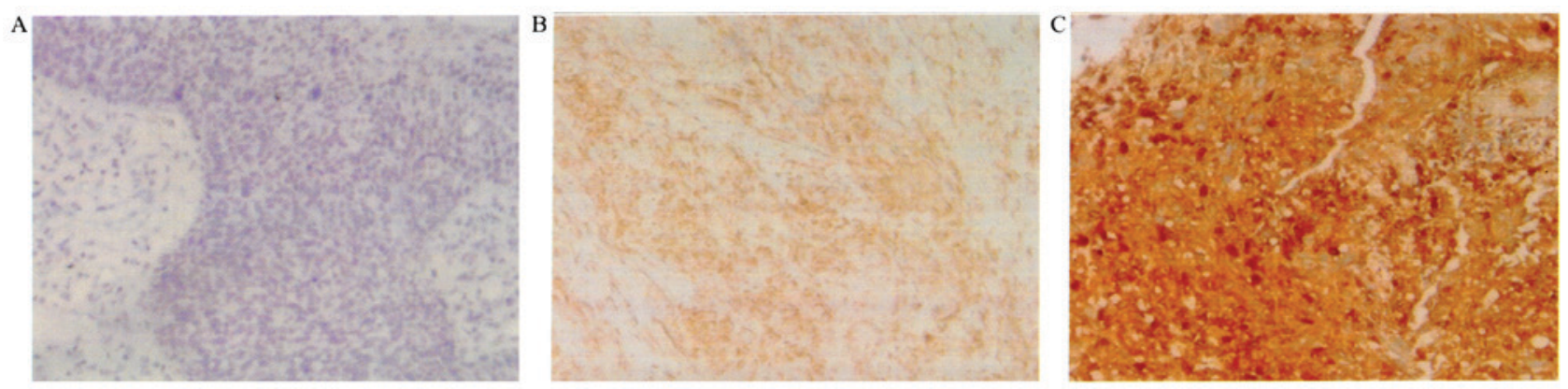

Figure 1. Immunohistochemical staining of UCP2 in locally advanced cervical cancer. (A) A negative control was performed without primary antibody. Scores of (B) 6 and (C) 12 were obtained in the presence of a primary antibody against UCP2. Hematoxylin staining. Magnification, $\mathrm{x} 400$. UCP2, uncoupling protein 2 .

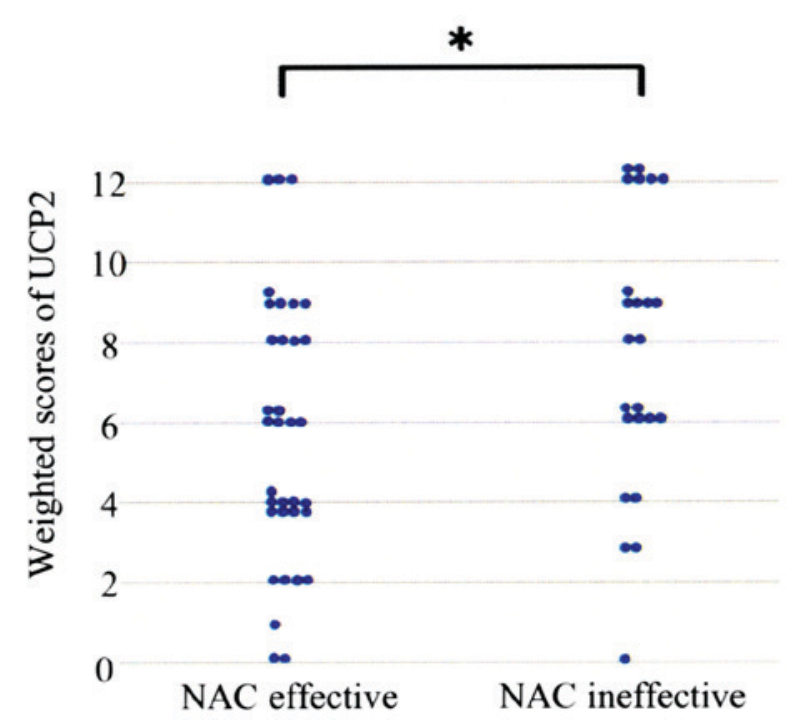

Figure 2. Weighted scores for UCP2 expression in tumor samples from patients with locally advanced cervical cancer. ${ }^{*} \mathrm{P}=0.038$ (Mann-Whitney $\mathrm{U}$ test). UCP2, uncoupling protein 2; NAC, neoadjuvant chemotherapy.

\section{Results}

Patients' characteristics. A total of 58 patients with locally advanced uterine cervical cancer were divided into two groups: The NAC effective group $(n=34)$ and the NAC ineffective group $(n=24)$. Table I contains patients' age, FIGO stage, histology and tumor size details. There were no significant differences in these parameters between the two groups.

UCP2 expression in uterine cervical cancer tissue. Cytoplasmic expression of UCP2 was observed in tumor cells (Fig. 1). Table II shows the UCP2 weighted scores in the tissues of the two patient groups. The means of weighted scores in the NAC effective and ineffective groups were 5.71 and 7.63, respectively. The UCP2 weighted score was significantly higher in the NAC ineffective group compared with that in the NAC effective group ( $\mathrm{P}=0.038$; Table II and Fig. 2).

Next, cases were divided into two groups based on their UCP2 expression levels: The low UCP2 expression group 
Table II. Weighted scores for uncoupling protein 2 expression in the NAC effective and ineffective groups.

\begin{tabular}{|c|c|c|}
\hline \multirow[b]{2}{*}{ Weighted score } & \multicolumn{2}{|c|}{ No. of patients } \\
\hline & NAC effective ${ }^{a}$ & NAC ineffective ${ }^{b}$ \\
\hline 0 & 2 & 1 \\
\hline 1 & 1 & 0 \\
\hline 2 & 4 & 0 \\
\hline 3 & 0 & 2 \\
\hline 4 & 9 & 2 \\
\hline 6 & 6 & 6 \\
\hline 8 & 4 & 2 \\
\hline 9 & 5 & 5 \\
\hline 12 & 3 & 6 \\
\hline Total & 34 & 24 \\
\hline Mean & 5.71 & 7.63 \\
\hline
\end{tabular}

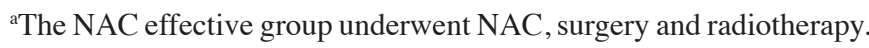
${ }^{\text {b}}$ The NAC ineffective group underwent NAC and radiotherapy only. NAC, neoadjuvant chemotherapy.

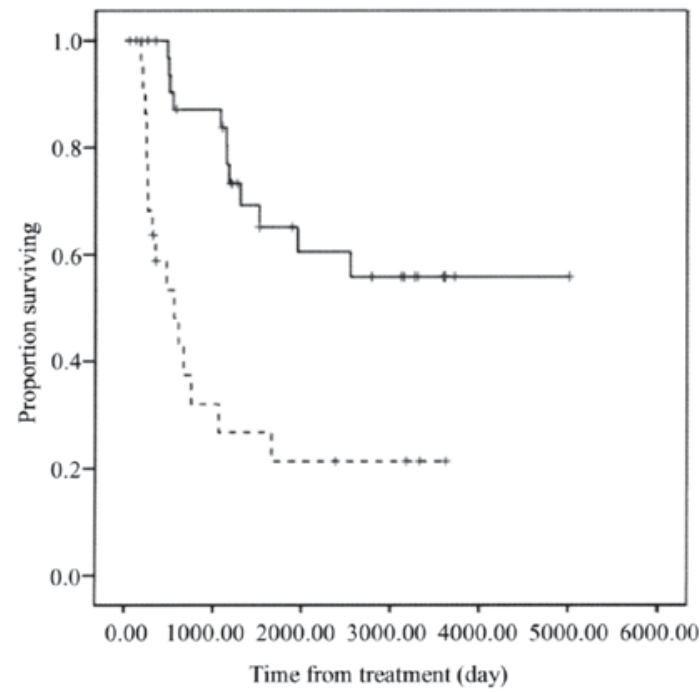

Figure 3. Overall survival rate in NAC effective group (dashed line; $n=34$ ) and NAC ineffective group (solid line; $\mathrm{n}=24$ ). $\mathrm{P}<0.001$ (Kaplan-Meier and log-rank tests). NAC, neoadjuvant chemotherapy.

(weighted score, 0-4) and the high UCP2 expression group (weighted score, 6-12). Table III lists the characteristics of the high and low expression groups, with analyses revealing no significant differences between the two groups.

NAC effectiveness correlates with UCP2 expression. Within the low UCP2 expression group, 16 cases (76\%) belonged to the NAC effective group, while $5(24 \%)$ belonged to the NAC ineffective group. In the high UCP2 expression group, 18 cases (49\%) belonged to the NAC effective group and $19(51 \%)$ to the NAC ineffective group. The low UCP2 expression group was more sensitive to NAC than the high UCP2 expression group $(\mathrm{P}=0.041$; Table IV).

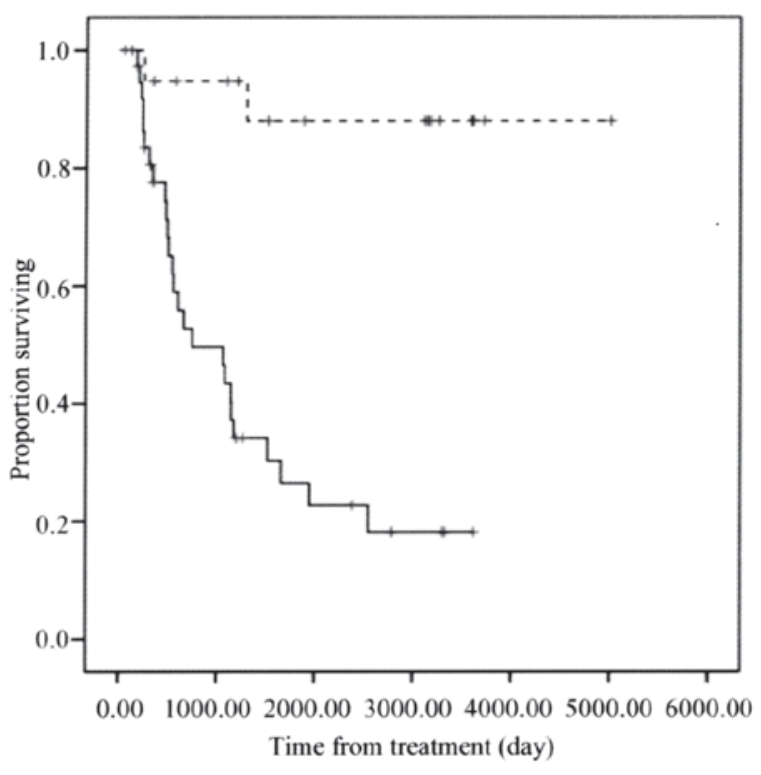

Figure 4. Overall survival rate in the low UCP2 expression (broken line; $\mathrm{n}=21$ ) and high UCP2 expression (solid line; $\mathrm{n}=37$ ) groups. $\mathrm{P}<0.001$ (Kaplan-Meier and log-rank tests). UCP2, uncoupling protein 2.

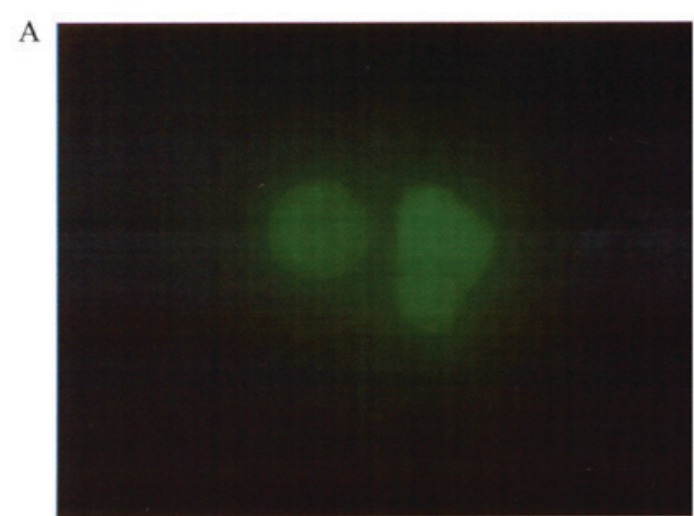

$\mathrm{B}$

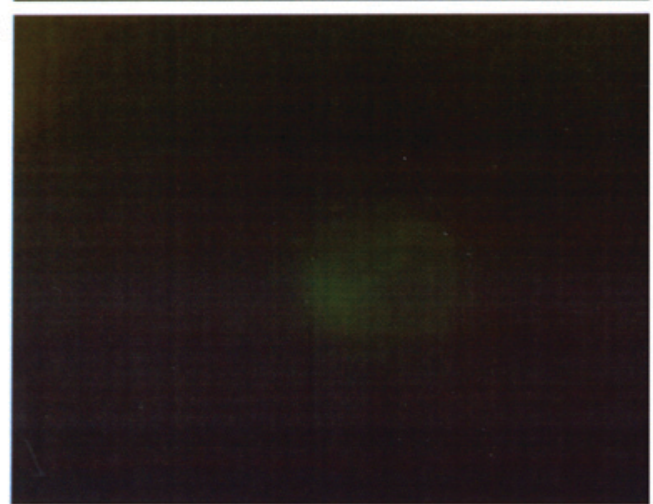

Figure 5. Expression of UCP2 protein in uterine cervical cancer Ca Ski cells, as confirmed by immunofluorescence staining of UCP2 in these cells. Ca Ski cells were cultured (A) without or (B) with $1 \mu \mathrm{M}$ genipin for $24 \mathrm{~h}$, and then stained with an anti-UCP2 antibody conjugated to a green fluorophore (original magnification, $\mathrm{x} 400$ ). UCP2, uncoupling protein 2.

Survival. The NAC effective group exhibited significantly improved overall survival compared with that of the NAC ineffective group $(\mathrm{P}<0.001$; Fig. 3). Furthermore, the low UCP2 expression group exhibited significantly improved 
Table III. Characteristics of patients in the low and high UCP2 expression groups.

\begin{tabular}{lccc}
\hline & \multicolumn{3}{c}{ No. of patients } \\
\cline { 2 - 4 } Characteristics & UCP2 expression (score $\leq 4)$ & UCP2 expression (score $\geq 6)$ & $0.594^{\mathrm{a}}$ \\
\hline No. of patients & 21 & 37 & P-value \\
Age (years) & $51.7 \pm 12.4$ & $49.8 \pm 12.5$ & $0.447^{\mathrm{b}}$ \\
Mean \pm SD & $24-68$ & $24-69$ & $0.759^{\mathrm{b}}$ \\
Range & & 1 & \\
FIGO stage & 0 & 36 & $0.144^{\mathrm{a}}$ \\
IIIA & 21 & 31 & 5 \\
IIIB & 17 & 1 & \\
Histology & 3 & 0 & \\
SCC & 0 & $54.0 \pm 17.3$ & \\
A & 1 & & \\
AS & & & \\
Others & $47.0 \pm 15.9$ & & \\
Tumor size (mm) & & & \\
Mean \pm SD & &
\end{tabular}

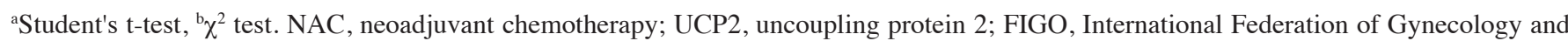
Obstetrics; SCC, squamous cell carcinoma; A, adenocarcinoma; AS, adenosquamous carcinoma; SD, standard deviation.

Table IV. Number of patients with low and high uncoupling protein 2 expression in the NAC effective and ineffective groups.

\begin{tabular}{lcc}
\hline UCP2 expression & NAC+OP+R, no. (\%) & NAC+R, no. (\%) \\
\hline Low expression (score $\leq 6)$ & $16(76)$ & $5(24)$ \\
High expression (score $\geq 8)$ & $18(49)$ & $19(51)$ \\
\hline
\end{tabular}

${ }^{a} \chi^{2}$ test. $\mathrm{NAC}+\mathrm{OP}+\mathrm{R}$, neoadjuvant chemotherapy + surgery + radiotherapy; $\mathrm{NAC}+\mathrm{R}$, neoadjuvant chemotherapy + radiotherapy.

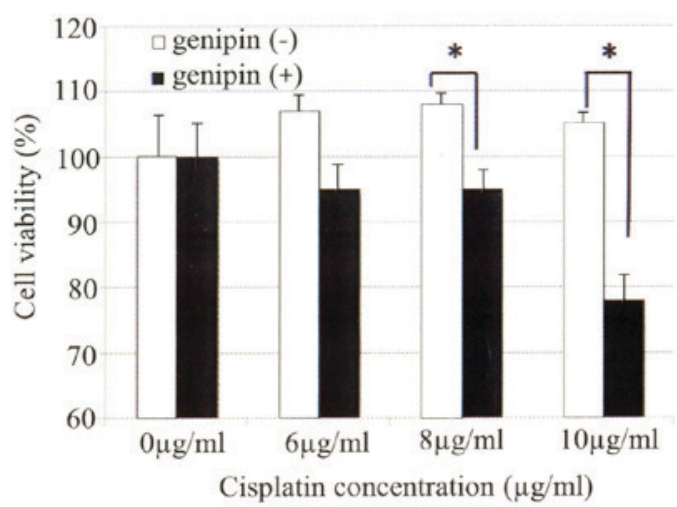

Figure 6. Ca Ski cell sensitivity to cisplatin in the presence or absence of genipin-mediated uncoupling protein 2 depletion. "P<0.05 (Student's t-test).

overall survival compared with that of the high UCP2 expression group $(\mathrm{P}<0.001$; Fig. 4).

Inhibition of UCP 2 by genipin enhances the sensitivity of cervical cancer cells to cisplatin. The expression of
UCP2 protein in the uterine cervical cancer cell line Ca Ski was confirmed by immunofluorescence analysis. UCP2 protein expression in $\mathrm{Ca}$ Ski cells was almost completely eliminated following $24 \mathrm{~h}$ of incubation with $1 \mu \mathrm{M}$ genipin (Fig. 5A and B). Next, it was examined whether the sensitivity of uterine cervical cancer cells to cisplatin was affected by treatment with genipin. Genipin-mediated inhibition of UCP2 expression in Ca Ski cells significantly enhanced their sensitivity to cisplatin (Fig. 6).

\section{Discussion}

CCRT is regularly recommended for patients with locally advanced uterine cervical cancer. However, effective NAC can reduce tumor size, thus facilitating hysterectomy for locally advanced uterine cervical cancer (7). Such treatment can improve the prognosis of patients with locally advanced cervical cancer (7). However, NAC is ineffective in certain cases, leaving radiotherapy as the only treatment option, and thereby delaying the initiation of the core treatment and resulting in worse prognosis $(10,11)$. Therefore, the identification of prognostic factors that indicate the likely efficacy of 
NAC for patients with locally advanced uterine cervical cancer should improve patient prognosis.

UCPs are mitochondrial anion transporters, and mitochondrial uncoupling reduces the production of ROS $(18,19)$. UCP2 is broadly expressed in cancer cells, and the expression of $\mathrm{UCP} 2$ is associated with ROS levels in various tissues $(23,24)$. Cancer cells reduce ROS production through the expression of $\mathrm{UCP} 2$; thus, high expression of UCP2 may protect cells from oxidative stresses and cell damage (30,33). UCP 2 contributes to both carcinogenesis and chemoresistance $(28,29)$. Additionally, overexpression of UCP2 in cancer cells facilitates resistance to gemcitabine, while downregulation of UCP2 results in significantly increased cell death following chemotherapy (34).

The current study demonstrates a significant correlation between UCP2 expression and NAC effectiveness in patients with locally advanced uterine cervical cancer. Patients with low UCP2 expression tended to be sensitive to NAC, and were able to undergo surgery following NAC. The overall survival time was significantly longer in the NAC effective group compared with that in the NAC ineffective group. Similarly, the overall survival time was significantly longer in the low UCP2 expression group compared with that in the high UCP2 expression group.

These results suggest that UCP2 expression levels in patients with locally advanced uterine cervical cancer are associated with the likely effectiveness of NAC. Therefore, $\mathrm{UCP} 2$ represents a potential predictive marker of whether NAC is likely to be effective in patients with locally advanced uterine cervical cancer.

The present study revealed that the proliferation of $\mathrm{Ca}$ Ski cells was suppressed by the addition of genipin following chemotherapy. This is consistent with previous reports using other cancer cells $(24,28,29)$. The present study is the first to report a correlation between UCP2 expression and NAC efficacy for locally advanced uterine cervical cancer.

In summary, UCP2 expression may become a predictive marker of whether NAC is effective for patients with locally advanced uterine cervical cancer. Such knowledge could be helpful for improving the prognosis of patients with locally advanced uterine cervical cancer.

\section{References}

1. Jemal A, Bray F, Center MM, Ferlay J, Ward E and Forman D: Global cancer statistics. CA Cancer J Clin 61: 69-90, 2011.

2. Pecorelli S: Revised FIGO staging for carcinoma of the vulva, cervix, and endometrium. Int J Gynaecol Obstet 105: 103-104, 2009.

3. Ebina Y, Yaegashi N, Katabuchi H, Nagase S, Udagawa Y, Hachisuga T, Saito T, Mikami M, Aoki Y and Yoshikawa H: Japan Society of Gynecologic Oncology guidelines 2011 for the treatment of uterine cervical cancer. Int J Clin Oncol 20 : 240-248, 2015

4. National comprehensive cancer network: NCCN clinical practice guidelines in oncology-cervical cancer-version II, 2013.

5. Morris M, Eifel PJ, Lu J, Grigsby PW, Levenback C, Stevens RE, Rotman M, Gershenson DM and Mutch DG: Pelvic radiation with concurrent chemotherapy compared with pelvic and para-aortic radiation for high-risk cervical cancer. N Engl J Med 340: 1137-1143, 1999

6. Eifel PJ, Winter K, Morris M, Levenback C, Grigsby PW, Cooper J, Rotman M, Gershenson D and Mutch DG: Pelvic irradiation with concurrent chemotherapy versus pelvic and para-aortic irradiation for high-risk cervical cancer: An update of radiation therapy oncology group trial (RTOG) 90-01. J Clin Oncol 22: 872-880, 2004.
7. Ishiko O, Sumi T, Yasui T, Matsumoto Y, Kawamura N, Ogita S, Kamino T, Nakamura K and Yamada R: Balloon-occluded arterial infusion chemotherapy, simple total hysterectomy, and radiotherapy as a useful combination-therapy for advanced cancer of the uterine cervix. Oncol Rep 7: 141-144, 2000.

8. Souhami L, Gil RA, Allan SE, Canary PC, Araújo CM, Pinto LH and Silveira TR: A randomized trial of chemotherapy followed by pelvic radiation therapy in stage IIIB carcinoma of the cervix. J Clin Oncol 9: 970-977, 1991.

9. Tattersall MH,Lorvidhaya V, Vootiprux V, Cheirsilpa A, Wong F, Azhar T, Lee HP, Kang SB, Manalo A, Yen MS, et al: Randomized trial of epirubicin and cisplatin chemotherapy followed by pelvic radiation in locally advanced cervical cancer. Cervical cancer study group of the Asian Oceanian clinical oncology association. J Clin Oncol 13: 444-451, 1995.

10. Ishiko O, Sumi T, Yasui T, Matsumoto Y, Ogita S, Kaminou T, Nakamura $\mathrm{K}$ and Yamada R: Tumor marker and MR imaging criteria for evaluating the efficacy of cyclic balloon-occluded arterial infusion for advanced cancer of the uterine cervix. Oncol Rep 7: 827-830, 2000.

11. Ishiko O, Sumi T, Yoshida H, Ogita S and Yamada R: Expression of apoptosis regulatory proteins in advanced cancer of the uterine cervix after cyclic balloon-occluded arterial infusion chemotherapy. Int J Oncol 18: 1151-1155, 2001.

12. Okamoto E, Sumi T, Misugi F, Nobeyama H, Hattori K, Yoshida H, Matsumoto Y, Yasui T, Honda K and Ishiko O: Expression of apoptosis-related proteins in advanced uterine cervical cancer after balloon-occluded arterial infusion chemotherapy as an indicator of the efficiency of this therapy. Int J Mol Med 15: 41-47, 2005.

13. Nobeyama H, Sumi T, Misugi F, Okamoto E, Hattori K, Matsumoto Y, Yasui T, Honda K, Iwai K and Ishiko O: Association of HPV infection with prognosis after neoadjuvant chemotherapy in advanced uterine cervical cancer. Int J Mol Med 14: 101-105, 2004.

14. Benedetti Panici P, Bellati F, Manci N, Pernice M, Plotti F, Di Donato V, Calcagno M, Zullo MA, Muzii L and Angioli R: Neoadjuvant chemotherapy followed by radical surgery in patients affected by FIGO stage IVA cervical cancer. Ann Surg Oncol 14: 2643-2648, 2007.

15. Pelicano H, Carney D and Huang P: ROS stress in cancer cells and therapeutic implications. Drug Resist Updat 7: 97-110, 2004.

16. Alexandre J, Batteux F, Nicco C, Chéreau C, Laurent A, Guillevin L, Weill B and Goldwasser F: Accumulation of hydrogen peroxide is an early and crucial step for paclitaxel-induced cancer cell death both in vitro and in vivo. Int J Cancer 119: 41-48, 2006.

17. Fruehauf JP and Meyskens FL Jr: Reactive oxygen species: A breath of life or death? Clin Cancer Res 13: 789-794, 2007.

18. Boss O, Muzzin P and Giacobino JP: The uncoupling proteins, a review. Eur J Endocrinol 139: 1-9, 1998

19. Fleury $C$ and Sanchis D: The mitochondrial uncoupling protein-2: Current status. Int J Biochem Cell Biol 31: 1261-1278, 1999.

20. Baffy G: Uncoupling protein-2 and cancer. Mitochondrion 10: 243-252, 2010.

21. Echtay KS, Murphy MP, Smith RA, Talbot DA and Brand MD: Superoxide activates mitochondrial uncoupling protein 2 from the matrix side. Studies using targeted antioxidants. J Biol Chem 277: 47129-47135, 2002.

22. Hoang T, Smith MD and Jelokhani-Niaraki M: Toward understanding the mechanism of ion transport activity of neuronal uncoupling proteins UCP2, UCP4, and UCP5. Biochemistry 51: 4004-4014, 2012.

23. Carretero MV, Torres L, Latasa U, Garcia-Trevijano ER, Prieto J, Mato JM and Avila MA: Transformed but not normal hepatocytes express UCP2. FEBS Lett 439: 55-58, 1998.

24. Horimoto M, Resnick MB, Konkin TA, Routhier J, Wands JR and Baffy G: Expression of uncoupling protein-2 in human colon cancer. Clin Cancer Res 10: 6203-6207, 2004.

25. Duval C, Nègre-Salvayre A, Dogilo A, Salvayre R, Pénicaud L and Casteilla L: Increased reactive oxygen species production with antisense oligonucleotides directed against uncoupling protein 2 in murine endothelial cells. Biochem Cell Biol 80: 757-764, 2002.

26. Mattiasson G, Shamloo M, Gido G, Mathi K, Tomasevic G, Yi S, Warden CH, Castilho RF, Melcher T, Gonzalez-Zulueta M, et al: Uncoupling protein-2 prevents neuronal death and diminishes brain dysfunction after stroke and brain trauma. Nat Med 9: 1062-1068, 2003. 
27. Teshima Y, Akao M, Jones SP and Marbán E: Uncoupling protein-2 overexpression inhibits mitochondrial death pathway in cardiomyocytes. Circ Res 93: 192-200, 2003.

28. Dalla Pozza E, Fiorini C, Dando I, Menegazzi M, Sgarbossa A Costanzo C, Palmieri M and Donadelli M: Role of mitochondrial uncoupling protein 2 in cancer cell resistance to gemcitabine. Biochim Biophys Acta 1823: 1856-1863, 2012.

29. Mailloux RJ, Adjeitey CN and Harper ME: Genipin-induced inhibition of uncoupling protein-2 sensitizes drug-resistant cancer cells to cytotoxic agents. PLoS One 5: e13289, 2010.

30. Derdák Z, Fülöp P, Sabo E, Tavares R, Berthiaume EP Resnick MB, Paragh G, Wands JR and Baffy G: Enhanced colon tumor induction in uncoupling protein-2 deficient mice is associated with NF-kappaB activation and oxidative stress. Carcinogenesis 27: 956-961, 2006.

31. Tsuji K, Yamada R, Kawabata M, Mitsuzane K, Sato M, Iwahashi M, Kitayama S and Nakano R: Effect of balloon occluded arterial infusion of anticancer drugs on the prognosis of cervical cancer treated with radiation therapy. Int J Radiat Oncol Biol Phys 32: 1337-1345, 1995.
32. Sinicrope FA, Ruan SB, Cleary KR, Stephens LC, Lee JJ and Levin B: Bcl-2 and p53 oncoprotein expression during colorectal tumorigenesis. Cancer Res 55: 237-241, 1995.

33. Collins P, Jones C, Choudhury S, Damelin L and Hodgson $\mathrm{H}$ : Increased expression of uncoupling protein 2 in HepG 2 cells attenuates oxidative damage and apoptosis. Liver Int 25: 880-887, 2005.

34. Dalla Pozza E, Fiorini C, Dando I, Menegazzi M, Sgarbossa A, Costanzo C, Palmieri M and Donadelli M: Role of mitochondrial uncoupling protein 2 in cancer cell resistance to gemcitabine. Biochim Biophy Acta 1823: 1856-1863, 2012. 